\title{
Motorcycle helmets and cervical spine injuries: a 5-year experience at a Level 1 trauma center
}

\author{
Paul S. Page, MD, Zhikui Wei, MD, PhD, and Nathaniel P. Brooks, MD \\ Department of Neurological Surgery, University of Wisconsin Hospitals and Clinics, Madison, Wisconsin
}

\begin{abstract}
OBJECTIVE Motorcycle helmets have been shown to decrease the incidence and severity of traumatic brain injury due to motorcycle crashes. Despite this proven efficacy, some previous reports and speculation suggest that helmet use is associated with a higher likelihood of cervical spine injury (CSI). In this study, the authors examine 1061 cases of motorcycle crash victims who were treated during a 5-year period at a Level 1 trauma center to investigate the association of helmet use with the incidence and severity of CSI. The authors hypothesized that wearing a motorcycle helmet during a motorcycle crash is not associated with an increased risk of CSI and may provide some protective advantage to the wearer.
\end{abstract}

METHODS The authors performed a retrospective review of all cases in which the patient had been involved in a motorcycle crash and was evaluated at a single Level 1 trauma center in Wisconsin between January 1, 2010, and January 1, 2015. Biometric, clinical, and imaging data were obtained from a trauma registry database. The patients were then divided into 2 distinct groups based on whether or not they were wearing helmets at the time of the accident. Baseline and functional characteristics were compared between the 2 groups. The Student t-test was used for continuous variables, and Pearson's chi-square analysis was used for categorical variables.

RESULTS In total, 1061 patient charts were examined containing data on 738 unhelmeted $(69.6 \%)$ and 323 helmeted $(30.4 \%)$ motorcycle riders. On average, helmeted riders had a much lower Injury Severity Score $(p<0.001)$. Cervical spine injury occurred in 114 unhelmeted riders (15.4\%) compared with only 24 helmeted riders $(7.4 \%)(p<0.001)$, with an adjusted odds ratio of $2.3(95 \% \mathrm{Cl} 1.44-3.61, p=0.0005)$. In the unhelmeted group, $10.8 \%$ of patients were found to have a cervical spine fracture compared with only $4.6 \%$ of patients in the helmeted group $(p=0.001)$. Additionally, ligamentous injury occurred more frequently in unhelmeted riders $(1.9 \%$ vs $0.3 \%, p=0.04)$. No difference was found in the occurrence of cervical strain, cord contusion, or nerve root injury (all $p>0.05$ ).

CONCLUSIONS The results of this study demonstrate a statistically significant lower likelihood of suffering a CSI among helmeted motorcyclists. Unhelmeted riders sustained a statistically significant higher number of vertebral fractures and ligamentous injuries. The study findings reported here confirm the authors' hypothesis that helmet use does not increase the risk of developing a cervical spine fracture and may provide some protective advantage.

https://thejns.org/doi/abs/10.3171/2017.7.SPINE17540

KEY WORDS cervical spine; motorcycle; craniocerebral trauma; neck injuries

$\mathrm{M}$ OTORCYCLE helmet laws frequently have been a point of contention over the past 50 years. Although certain safety standards have been implemented by lawmakers to diminish the inherent risks of motorcycle use, morbidity and mortality continue to be significantly associated with this activity. In 2015 alone, 88,000 motorcyclists were injured and 4594 were killed according to the National Highway Traffic Safety Admin- istration. ${ }^{3}$ Compared with automobile drivers, motorcyclists are 30 times more likely to die in a traffic-related accident. ${ }^{5}$ Due to the increased risk of head injuries associated with motorcycle use, the value of legislation requiring helmet use is frequently debated. Currently, no national mandatory helmet law exists in the United States. As a result, state legislatures have implemented a spectrum of helmet laws ranging from no mandatory use to a univer-

ABBREVIATIONS AIS = Abbreviated Injury Scale; $A S I A=$ American Spinal Injury Association; $C S I$ = cervical spine injury.

SUBMITTED May 10, 2017. ACCEPTED July 28, 2017.

INCLUDE WHEN CITING Published online March 6, 2018; DOI: 10.3171/2017.7.SPINE17540. 
sal helmet law requiring all motorcyclists to wear helmets when riding. Like 21 other states, Wisconsin currently has a partial helmet law, which requires only individuals under the age of 18 years and persons with instructional permits to wear helmets.

Opponents of universal helmet laws often cite as reasons the importance of inherent freedom of choice and adverse consequences of helmet use such as limitation of vision and possible increased risk of cervical spine injuries (CSIs). ${ }^{8,17}$ The latter argument is based on the theory that increased weight on the head results in increased torque on the cervical spine. While little evidence of this theory exists, an article by Goldstein in which the author concluded that "past a critical impact speed helmets increase the severity of neck injuries" is frequently cited as evidence. ${ }^{6}$ Recent efforts by national motorcycle lobbyists have resulted in either the complete repeal of a prior universal helmet law or the institution of more lenient laws regarding helmet use in Arkansas, Texas, Kentucky, Louisiana, and Florida. Since these changes were implemented, a dramatic increase in overall fatalities attributable to motorcycle crashes has occurred in some states, specifically Louisiana. $^{5}$

In the present study, we hypothesized that wearing a motorcycle helmet during a crash is not associated with an increased risk of CSI. Specifically, we examined the incidence, severity, and functional outcomes of CSI in patients involved in motorcycle accidents, and we compared these variables between patients who had worn helmets during the accident and patients who had not worn helmets. To do so, we retrospectively reviewed data at a Level 1 academic tertiary referral center in Wisconsin over a 5 -year period.

\section{Methods}

We conducted a retrospective patient chart review for all motorcycle crash victims who were evaluated at the University of Wisconsin Hospital between 2010 and 2015 by examining the TraumaBase database maintained by Clinical Data Management. Trained trauma registrars enrolled patients into this registry at the time of their initial encounters according to guidelines of the National Trauma Data Bank and Trauma Quality Improvement national standards supported by the American College of Surgeons. In September 2016, we queried records from the selected time frame using definitions, appropriate ICD-9 codes, and Abbreviated Injury Scale (AIS; https://www. aaam.org/abbreviated-injury-scale-ais/) scores from the 2016 National Trauma Data Standard Bank data dictionary. Through this database examination, we identified 1064 patients as having been involved in a motor vehicle crash in which a motorcycle was involved. No special designation was made regarding speed, and there was no differentiation made between passengers and drivers. Upon identification of these patients, the ICD-9 codes and AIS scores associated with the patients' hospitalizations were generated and reviewed by 2 authors (P.S.P. and Z.W.) for the inclusion criteria of spine fractures, spinal cord injuries, ligamentous injuries, or other unspecified injuries to the cervical spine. Additionally, AIS scores beginning with 6502,6302 , and 6402 were queried to ensure that all patients were included. After we identified all patients within these inclusion criteria, all available imaging and radiology reports of the cervical spine were reviewed to ensure accurate characterization of the pathological conditions that were present. Patients were divided into 2 distinct groups-helmeted and unhelmeted-based on whether they wore protective head covering at the time of injury. Baseline and functional characteristics were compared between the 2 groups. Neurological function outcomes were obtained through documentation of the results of each patient's physical examination at the time of discharge. Crude mortality was defined as any death occurring during the hospitalization immediately following the incident.

The Student t-test was used for continuous variables and the Pearson chi-square test was used for categorical variables in the statistical analyses. A p value of $<0.05$ was deemed statistically significant for the purposes of this study. All statistical analyses were performed using Wizard version 1.8.23. Logistic regression was used to evaluate the association between helmeted and unhelmeted riders and the presence of CSI. The model fit did not improve with the addition of demographic variables (age, race, and sex), and thus in the final model the only variables included were helmeted versus unhelmeted as a predictor variable and the presence of CSI as an outcome variable.

\section{Results}

Of the 1061 patients treated for injuries due to motorcycle crashes over the 5-year period, 738 (69.6\%) were unhelmeted, whereas 323 (30.3\%) were helmeted. In the patient groups, 607 patients $(82.3 \%)$ in the unhelmeted group and 280 patients $(86.7 \%$ ) in the helmeted group were male (Table 1). The mean age of patients in the helmeted group was $40.6 \pm 17.1$ years, which is significantly younger than the mean age in the unhelmeted group ( $44.0 \pm 14.8$ years). Ethnicity was predominantly white in both groups, and no significant differences in demographics were found between the patient groups.

In the unhelmeted group, $114(15.4 \%)$ patients were found to have some type of CSI compared with $24 \mathrm{pa}-$ tients $(7.4 \%)$ in the helmeted group $(p<0.001)$. This finding demonstrates statistically significant decreased odds of helmeted riders suffering from a CSI (OR 2.28, 95\% CI $1.44-3.61, \mathrm{p}=0.0005)$.

On average, helmeted riders had a much lower Injury Severity Score $(p<0.001)$. There was no difference in Injury Severity Scores between the 2 groups when the focus was on patients in whom a CSI had occurred $(p=0.99)$.

As shown in Fig. 1, 10.8\% of patients in the unhelmeted group sustained a cervical spine fracture compared with only $4.6 \%$ of patients in the helmeted group $(\mathrm{p}=0.001)$. Unhelmeted riders sustained a significantly higher number of fractures at spinal levels C-1 and C-5 ( $p=0.04$ and $\mathrm{p}=0.01$, respectively) (Table 2). Of those with a CSI, a significantly higher proportion of ligamentous injuries occurred in patients in the unhelmeted group $(1.9 \%$ vs $0.3 \%$, $\mathrm{p}=0.04)$. No statistically significant differences between groups were found in the rates of cord contusion, nerve 
TABLE 1. Patient demographics and injury severity characteristics of helmeted and unhelmeted motorcyclists involved in motor vehicle accidents

\begin{tabular}{|c|c|c|c|c|c|c|}
\hline \multirow[b]{2}{*}{ Variable } & \multicolumn{3}{|c|}{ Total $(n=1061)$} & \multicolumn{3}{|c|}{ Patients w/ CSI $(n=138)$} \\
\hline & Unhelmeted $(n=738)$ & Helmeted $(n=323)$ & p Value & Unhelmeted $(n=114)$ & Helmeted $(n=24)$ & p Value \\
\hline Male & $607(82.3)$ & $280(86.7)$ & 0.072 & $89(78.9)$ & $22(88.0)$ & 0.13 \\
\hline Age in yrs & $44.01 \pm 14.81$ & $40.55 \pm 17.09$ & 0.002 & $44.48 \pm 12.7$ & $33.96 \pm 15.92$ & 0.005 \\
\hline \multicolumn{7}{|l|}{ Race/ethnicity } \\
\hline White & 690 & 301 & 0.850 & 112 & 21 & 0.011 \\
\hline African American & 14 & 12 & 0.078 & 1 & 3 & 0.002 \\
\hline Asian & 11 & 3 & 0.46 & 1 & 0 & 0.65 \\
\hline Hispanic & 5 & 1 & 0.46 & 0 & 0 & \\
\hline Other/NA & 18 & 6 & 0.56 & 0 & 0 & \\
\hline \multicolumn{7}{|l|}{ Discharge disposition } \\
\hline Home & 547 & 278 & $<0.001$ & 64 & 20 & 0.013 \\
\hline Acute rehabilitation & 70 & 15 & 0.008 & 27 & 3 & 0.23 \\
\hline SNF & 43 & 18 & 0.87 & 7 & 0 & 0.21 \\
\hline LTAC & 4 & 2 & 0.88 & 0 & 0 & \\
\hline Other & 40 & 9 & 0.06 & 11 & 0 & 0.11 \\
\hline Deceased & 27 & 1 & 0.002 & 5 & 1 & 0.96 \\
\hline Injury Severity Score & $13.85 \pm 11.45$ & $9.67 \pm 8.58$ & $<0.001$ & $19.73 \pm 13.48$ & $19.76 \pm 13.48$ & 0.99 \\
\hline ICU LOS & $1.61 \pm 4.56$ & $0.42 \pm 2.09$ & $<0.001$ & $9.68 \pm 10.30$ & $5.33 \pm 6.47$ & 0.01 \\
\hline Hospital LOS & $6.81 \pm 8.35$ & $4.65 \pm 5.75$ & $<0.001$ & $2.75 \pm 5.10$ & $1.42 \pm 4.01$ & 0.17 \\
\hline
\end{tabular}

ICU = intensive care unit; $L O S=$ length of stay; $L T A C=$ long-term acute care; NA = not available; $S N F=$ skilled nursing facility.

Values are number of patients (\%) or mean $\pm \mathrm{SD}$, unless otherwise indicated. Boldface type indicates statistical significance.

root injury, or cervical strain (all p >0.05; Fig. 1), although of the patients with CSI, cord contusion occurred more frequently in the patients in the unhelmeted group $(11.4 \%$ vs $8.3 \%$ ). The severity of spinal cord injuries was evaluat- ed using the American Spinal Injury Association (ASIA) scoring system. As shown in Table 3, most patients-helmeted and unhelmeted riders-at discharge were placed in the ASIA E category on initial presentation, and there

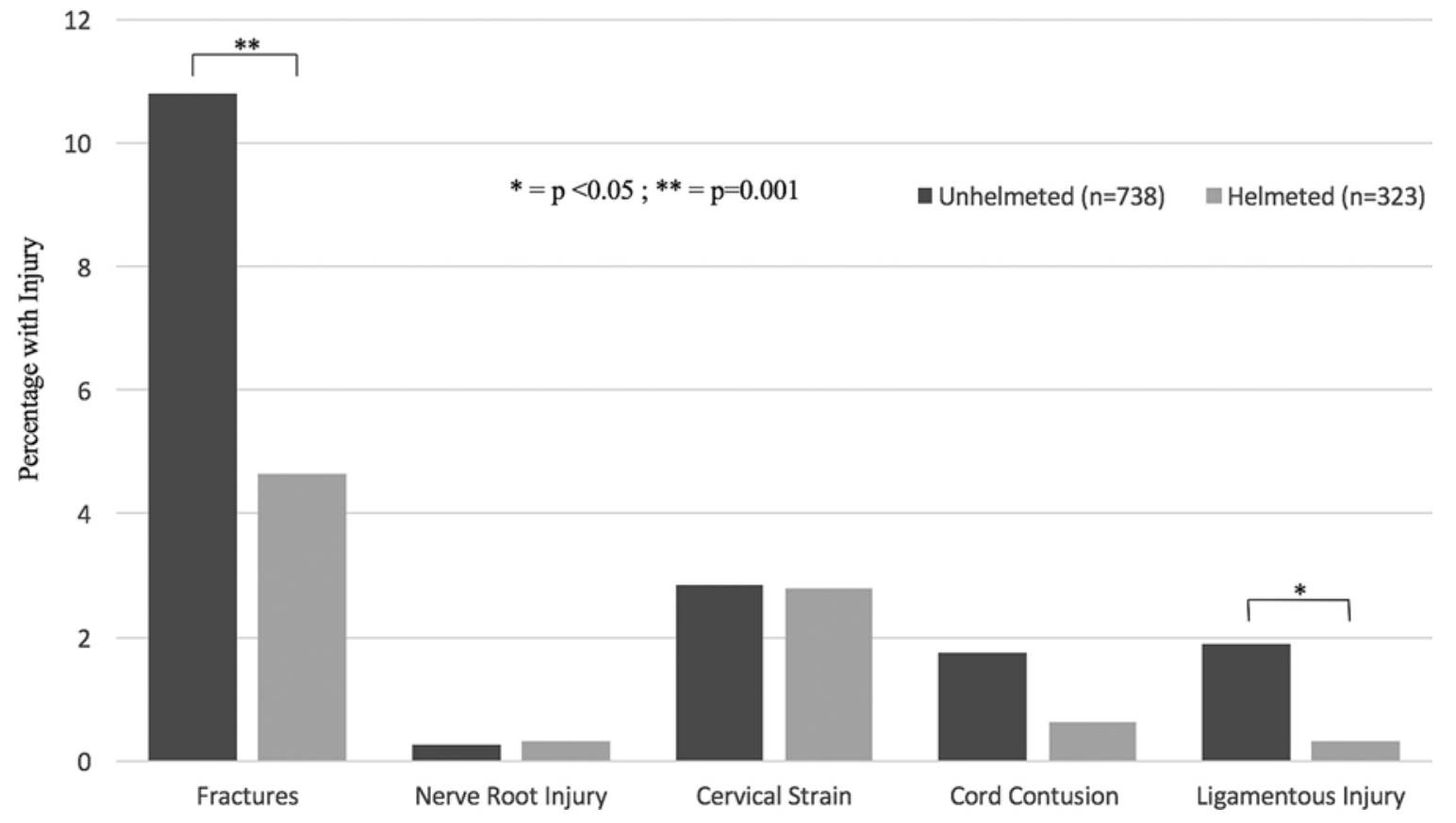

FIG. 1. Bar graph showing the characterization and distribution of CSIs in both helmeted and unhelmeted riders after motorcycle crashes. 
TABLE 2. Distribution of CSIs sustained by unhelmeted and helmeted motorcyclists

\begin{tabular}{cccc}
\hline Type of Injury & Unhelmeted $(\mathrm{n}=114)$ & Helmeted $(\mathrm{n}=24)$ & $\mathrm{p}$ Value \\
\hline Cervical fracture & 80 & 15 & $\mathbf{0 . 0 0 1}$ \\
\hline C-1 & 14 & 1 & $\mathbf{0 . 0 4}$ \\
\hline C-2 & 13 & 1 & 0.56 \\
\hline C-3 & 6 & 2 & 0.74 \\
\hline C-4 & 10 & 3 & 0.56 \\
\hline C-5 & 14 & 0 & 0.01 \\
\hline C-6 & 21 & 3 & 0.49 \\
\hline C-7 & 41 & 9 & 0.89 \\
\hline Nerve root injury & 2 & 1 & 0.91 \\
\hline Cervical strain & 21 & 9 & 0.96 \\
\hline Cord contusion & 13 & 2 & 0.15 \\
\hline Ligamentous & 14 & 1 & 0.04 \\
injury & & & \\
\hline
\end{tabular}

Values are the numbers of patients who sustained each type of injury, unless otherwise indicated. Patients may have sustained more than 1 injury, with the exception of patients with cervical strain, which by definition does not have any additional associated injury to the cervical spine. Boldface type indicates statistical significance.

was no difference in the distribution of ASIA scores between these 2 groups.

\section{Discussion}

The benefit of motorcycle helmets in the prevention of traumatic brain injury, reduction in crash-related mortality, and reduction in the cost of hospitalization is well documented and scientifically proven and has been readily accepted by the community at large. ${ }^{4,9,12}$ Despite these well-known benefits, there is significant resistance to universal helmet laws due to a theoretical increased risk of CSI, theoretical alterations in visuospatial awareness, and perceived impingement on personal freedom. While universal helmets laws have become more common throughout the world, including a universal helmet law in all European Union countries, these laws have actually become less stringent within the United States in recent years. Despite studies demonstrating equivocal rates of CSI, improved functional outcomes, and lower mortality rates in states with a motorcycle helmet law in place, there continues to be rigorous debate over this topic in state and federal legislatures. ${ }^{3}$

Although numerous arguments against a universal helmet law exist, the most scientifically debated point pertains to the biomechanical stresses that the cervical spine sustains in the helmeted rider during a motorcycle crash. While few sources have demonstrated that a helmet protects against CSI, the majority of studies reported in the literature have demonstrated that helmet use is certainly not associated with an increased risk of CSI. The article most commonly cited as an argument against universal helmets laws was published in $1986,{ }^{6}$ in that study, a physical model was used in conjunction with a retrospective evaluation of more than 1000 crash scene reconstructions and 644 motorcyclists. After conducting crash scene re-
TABLE 3. Comparison of neurological outcomes in helmeted and unhelmeted motorcyclists at the time of hospital discharge

\begin{tabular}{cccc}
\hline ASIA Score & Unhelmeted $(n=109)$ & Helmeted $(n=24)$ & $p$ Value \\
\hline A & 0 & 0 & \\
\hline B & 1 & 0 & 0.64 \\
\hline C & 1 & 0 & 0.64 \\
\hline D & 11 & 2 & 0.84 \\
\hline E & 90 & 22 & 0.11 \\
\hline UFC & 6 & 0 & 0.25 \\
\hline
\end{tabular}

UFC = unable to follow commands.

constructions and physical modeling, Goldstein concluded that helmet use at any speed greater than 13 miles per hour produces an unsafe physiological torque on the cervical spine that is out of proportion to what the normal musculoskeletal system undergoes routinely. This study has frequently received harsh criticism; its basic flaws include oversimplification of the vector model used and lack of documentation for the reported speed threshold of 13 miles per hour. ${ }^{16}$ Another study, which is less frequently cited, is the 2011 study by Ooi et al..$^{15}$ Although their study shows that certain crash types are associated with a higher risk of CSI and provides pertinent information on the biomechanical aspects of these CSIs, it is important to note that the study focuses on accidents occurring in Malaysia, where road conditions and traffic regulations are drastically different from those in the United States.

In direct opposition to the aforementioned studies, the majority of published papers demonstrate that helmet use conveys neither protective nor harmful biomechanical effects during an accident. ${ }^{11} \mathrm{~A}$ recent retrospective analysis conducted to evaluate the effects of the repeal of a universal helmet law in Florida demonstrated that helmet use did not significantly increase the risk of CSI in patients involved in motorcycle, moped, or bicycle accidents. ${ }^{7}$ These findings have been corroborated numerous times, including by researchers in Taiwan, who evaluated 110 patients and established no increased odds of CSI in unhelmeted compared with helmeted riders. ${ }^{10,11,14}$

Our study found a significantly higher incidence of CSI in unhelmeted riders compared with helmeted riders (15.4\% compared with $7.4 \%$, respectively, $\mathrm{p}<0.001)$ and lower odds of sustaining a CSI (OR 2.3, 95\% CI 1.44-3.61, $\mathrm{p}=0.0005)$. These findings were corroborated by the results of the largest study conducted to date, in which more than 62,000 patients were evaluated and helmeted riders were demonstrated to have a lower adjusted odds ratio and proportion of CSIs than nonhelmeted riders. ${ }^{2}$ While fewer studies have demonstrated that helmets convey a significant benefit in the prevention of CSI, our results strongly indicate that they serve a highly protective role.

Also of note of the patients who suffered a CSI, we found a higher incidence of cervical fractures in the unhelmeted group (70.2\%) than in the helmeted group (62.5\%) $(\mathrm{p}=0.001)$. This result has been corroborated by multiple other large studies with similar results. ${ }^{1}$ Although the incidence of fractures was evaluated in other earlier studies, we were able to evaluate the incidence of fractures at each 
spinal level specifically through a review of individual imaging reports.

This study does have limitations. First, it is a retrospective study with associated limitations of bias. However, the hypothesis of this study was not designed for the investigation of a treatment intervention but rather the association of a safety device in the development of prehospital injuries. Given the way the hypothesis was defined, the study design was appropriate. Second, the number of patients in the helmeted group presenting with CSIs was only 24 . Due to this limited number of patients, there are certainly aspects of our study, specifically details regarding injury patterns, that could be called into question and must be verified by future studies. Our study also does not account for patient details such as the number of fatalities that may have occurred in patients who died before being transported to the hospital for evaluation or receiving cervical spine imaging or further crash details such as speed. Additionally, as our study was conducted at a large regional Level 1 trauma center, a referral bias is inherently present. We recommend that future studies examine severity of injury and other pertinent outcome measures as an important way of characterizing CSIs; this should lead to a better understanding of the biomechanical stresses experienced by riders during motorcycle accidents.

\section{Conclusions}

In conclusion, helmeted motorcyclists demonstrated a significantly lower likelihood of sustaining a CSI. Additionally, unhelmeted riders demonstrated a proportionally higher number of cervical vertebral fractures. The results of this study demonstrate that motorcycle helmet use does not increase the risk of CSI. In addition, the results provide further evidence that helmet use should be implemented to reduce traumatic brain injury, crash-related mortality, cost of hospitalization, and CSI in motorcyclists.

\section{Acknowledgments}

We would like to acknowledge Ms. Kelly Jung and Dr. Suresh Agarwal for their efforts in the implementation and maintenance of the TraumaBase database, which was instrumental to this research. We would also like to thank Mr. Geng Li and Dr. Roxana Alexandridis for their help with data analysis.

\section{References}

1. Croce MA, Zarzaur BL, Magnotti LJ, Fabian TC: Impact of motorcycle helmets and state laws on society's burden: a national study. Ann Surg 250:390-394, 2009

2. Crompton JG, Bone C, Oyetunji T, Pollack KM, Bolorunduro $\mathrm{O}$, Villegas C, et al: Motorcycle helmets associated with lower risk of cervical spine injury: debunking the myth. $\mathbf{J}$ Am Coll Surg 212:295-300, 2011

3. Dao H, Lee J, Kermani R, Minshall C, Eriksson EA, Gross $\mathrm{R}$, et al: Cervical spine injuries and helmet laws: a population-based study. J Trauma Acute Care Surg 72:638-642, 2012

4. Eastridge BJ, Shafi S, Minei JP, Culica D, McConnel C, Gentilello L: Economic impact of motorcycle helmets: from impact to discharge. J Trauma 60:978-984, 2006

5. Eltorai AE, Simon C, Choi A, Hsia K, Born CT, Daniels
AH: Federally mandating motorcycle helmets in the United States. BMC Public Health 16:242, 2016

6. Goldstein JP: The effect of motorcycle helmet use on the probability of fatality and the severity of head and neck injuries. A latent variable framework. Eval Rev 10:355-375, 1986

7. Hooten KG, Murad GJ: Helmet use and cervical spine injury: a review of motorcycle, moped, and bicycle accidents at a level 1 trauma center. J Neurotrauma 31:1329-1333, 2014

8. Jones MM, Bayer R: Paternalism and its discontents: motorcycle helmet laws, libertarian values, and public health. Am J Public Health 97:208-217, 2007

9. Kraus JF, Peek C, McArthur DL, Williams A: The effect of the 1992 California motorcycle helmet use law on motorcycle crash fatalities and injuries. JAMA 272:1506-1511, 1994

10. Lin MR, Tsauo JY, Hwang HF, Chen CY, Tsai LW, Chiu WT: Relation between motorcycle helmet use and cervical spinal cord injury. Neuroepidemiology 23:269-274, 2004

11. Moskal A, Martin JL, Laumon B: Helmet use and the risk of neck or cervical spine injury among users of motorized twowheel vehicles. Inj Prev 14:238-244, 2008

12. Muller A: Florida's motorcycle helmet law repeal and fatality rates. Am J Public Health 94:556-558, 2004

13. National Highway Traffic Safety Administration: Traffic Safety Facts 2015. Washington, DC: U. S. Department of Transportation, 2016 (https://crashstats.nhtsa.dot.gov/Api/ Public/ViewPublication/812384) [Accessed September 27, 2017]

14. O'Connor PJ: Motorcycle helmets and spinal cord injury: helmet usage and type. Traffic Inj Prev 6:60-66, 2005

15. Ooi SS, Wong SV, Yeap JS, Umar R: Relationship between cervical spine injury and helmet use in motorcycle road crashes. Asia Pac J Public Health 23:608-619, 2011

16. Ouellet JV, Thom DR, Smith T, Hurt HH Jr: Helmets and neck in injuries in fatal motorcycle crashes, in 2013 International Motorcycle Safety Conference, Orlando, Florida, 2013. (https://www.msf-usa.org/downloads/ imsc2013/Oct17_Session2-Thom_Ouellet_Smith_HurtHelmets_and_Neck_Injuries_in_Fatal_Motorcycle Crashes_PAPER.pdf) [Accessed September 27, 2017]

17. Simon v Sargent, DC Mass 1972, 346 F. Supp. 277, affirmed 93 S.Ct. 463, 409 U.S. 1020, 34 L.Ed.2d 312

\section{Disclosures}

The authors report no conflict of interest concerning the materials or methods used in this study or the findings specified in this paper.

\section{Author Contributions}

Conception and design: Brooks, Page. Acquisition of data: Page, Wei. Analysis and interpretation of data: all authors. Drafting the article: all authors. Critically revising the article: Page. Reviewed submitted version of manuscript: Brooks, Page. Statistical analysis: Page, Wei. Administrative/technical/material support: Page. Study supervision: Brooks, Page.

\section{Supplemental Information}

Previous Presentations

This work was presented at the 2017 Annual AANS Meeting, Los Angeles, California, as an oral presentation on April 24, 2017.

\section{Correspondence}

Nathaniel Brooks: University of Wisconsin Hospitals and Clinics, Madison, WI.brooks@neurosurgery.wisc.edu. 